\title{
Bidirectional promoters in seed development and related hormone/stress responses
}

\author{
Sofia Kourmpetli ${ }^{1}$, Kate Lee ${ }^{2}$, Rachel Hemsley ${ }^{3}$, Pascale Rossignol ${ }^{4}$, Thaleia Papageorgiou ${ }^{1}$ and Sinéad Drea ${ }^{1 *}$
}

\begin{abstract}
Background: Bidirectional promoters are common in genomes but under-studied experimentally, particularly in plants. We describe a targeted identification and selection of a subset of putative bidirectional promoters to identify genes involved in seed development and to investigate possible coordinated responses of gene pairs to conditions important in seed maturation such as desiccation and ABA-regulation.

Results: We combined a search for 100-600 bp intergenic regions in the Arabidopsis genome with a cis-element based selection for those containing multiple copies of the G-box motif, CACGTG. One of the putative bidirectional promoters identified also contained a CE3 coupling element 5 bp downstream of one G-box and is identical to that characterized previously in the HVA1 promoter of barley. CE3 elements are significantly under-represented and under-studied in Arabidopsis. We further characterized the pair of genes associated with this promoter and uncovered roles for two small, previously uncharacterized, plant-specific proteins in Arabidopsis seed development and stress responses.
\end{abstract}

Conclusions: Using bioinformatics we identified putative bidirectional promoters involved in seed development and analysed expression patterns for a pair of plant-specific genes in various tissues and in response to hormones/stress. We also present preliminary functional analysis of these genes that is suggestive of roles in seed development.

Keywords: Arabidopsis thaliana, Bidirectional promoter, G-box, ABRE, Abscisic acid, Seed development, Desiccation, Stress response

\section{Background}

Bidirectional promoters are common in genomes [1] and have more recently been identified and examined in silico in the completed genomes of plants, including Arabidopsis $[2,3]$. The relevance and potential of these promoters in biotechnology has been documented [4-6], particularly for use in gene-stacking approaches where more than one gene is required to confer a particular trait trangenically or more than one trait is being conferred e.g. resistance to a suite of pests [7]. While researchers can engineer polar promoters to be bidirectional $[4,6]$, if we can characterize naturally occurring bidirectional promoters in plants these could provide a valuable alternative or at least a source of information on their mode of action in planta.

As well as applied and biotechnological relevance, the existence of bidirectional promoters has been recognized

\footnotetext{
* Correspondence: sd201@le.ac.uk

'Department of Biology, University of Leicester, University Road, Leicester LE1 $7 \mathrm{RH}, \mathrm{UK}$

Full list of author information is available at the end of the article
}

as a fundamental and complex means of transcriptional control $[8,9]$. Research in yeast revealed that the existence of bidirectional promoters was not only pervasive but the source of the majority of cryptic transcription in the organism and therefore the means of transcriptional regulation $[10,11]$.

Except for isolated examples of detailed experimental analyses of bidirectional promoters [12-15], virtually all the work published to date is bioinformatics-based and while this work has certainly highlighted the prevalence and potential importance of bidirectional promoters in areas from fundamental transcriptional control research to clinical relevance in cancer research $[8,9,16]$, it still remains to explore the functional relevance of this gene organization experimentally by focusing on specific gene pairs of interest. The bioinformatics/computationalbased criteria used to isolate a workable set of genes can vary depending on the desired outcome of the analyses and can involve coding and non-coding features - in this case we used both to identify putative bidirectional

\section{Biomed Central}


promoters regulating genes involved in seed development. Analysis of the divergently transcribed genes associated with a targeted set of bidirectional promoters is likely to lead to discovery of novel genes involved in development and/or previously undescribed relationships between genes of different functional categories in common or complementary processes/responses.

We used bioinformatics to search and identify a subset of putative bidirectional promoters that we predicted would regulate genes with roles in seed development. ABA is integral to plant seed development as a general process but mechanistically ABA mediates the conferral of desiccation tolerance and dormancy on seeds [17]. As such therefore there is extensive crosstalk between the stress responses of drought and cold as well as antagonistic interactions with the germination process [18]. The response to ABA is mediated by promoter motifs based on the ACGT core called ABREs (abscisic acid responsive elements) and including the G-box element (CACGTG). This element has been found in previously identified cases of bidirectional promoters which regulate genes involved in ABA response and seed development [19-21], as well as in promoters of genes regulated by light $[22,23]$. The identity of the nucleotides flanking the ACGT has been found to be an important determinant of the element's specificity [24,25]. The use of cis-elements such as ABREs in identifying genes involved in ABA and stress response has been previously described [26]. The G-box ABRE is often found in combination with other motifs, coupling elements (CE) that can be derived from or distinct from the ACGT core and are also involved in the seed/ABA regulation and responses to osmotic and coldtemperature stresses [18,27]. In addition, specific motifs associated with regulation by cold and dehydration have been classified as DRE/CRTs (dehydration response element/ c-repeat) derived from a CCGAC core sequence [28,29].

Previous work characterized two genes highly expressed in maturing seeds [30,31]. These genes are transcribed from an intergenic region (between start codons) of $411 \mathrm{bp}$ which contains three copies of the Gbox (CACGTG) motif involved in ABA-regulated seed development [20,30,31] (Additional file 1: Figure S1A). These genes, At4g16155 and At4g16160, encode a plastid outer envelope protein, OEP16-S, and a lipoamide dehydrogenase, ptLPD2, also localized to the plastid (in this case the stroma) [31]. Recent functional analyses of these genes revealed roles in metabolic fluctuation and arsenate sensitivity, respectively [32,33]. In addition, a divergent arrangement of a seed-expressed oleosin gene, $O L E 1$, and a peptide methionine sulfoxide reductase, PMSR, At4g25130 and At4g25140 respectively, was reported initially in Brassica napus and then characterised in Arabidopsis [21,34,35]. This promoter of 499 bp (between start codons) contained two copies of the G-box motif
(Additional file 1: Figure S1B). The PMSR protein is plastid-localised and involved in oxidative stress response while mutations in $O L E 1$ conferred cold tolerance [36,37].

We combined a search for a bidirectional gene arrangement with ABRE and associated cis-elements in the Arabidopsis genome and subsequently focused on a pair of plant-specific genes of unknown function that we characterised in detail. The identity and localisation of the genes identified in the bioinformatics search suggest that this gene arrangement might enable a means of concerted or complementary responses to stresses or environmental stimuli, such as drought or hormones, while the localization of the gene products to varied organelles could reflect a means of coordinating the complex intracellular interactions induced by stress conditions.

\section{Methods}

\section{Bioinformatic analyses}

Arabidopsis thaliana genes were downloaded from ENSEMBL plants 17, with headers including gene ID, transcript ID, coding sequence, chromosome name, transcript start, transcript end and strand. Putative bidirectional promoters were identified using in-house Perl scripts that searched header information for transcripts on opposite strands of the same chromosome that had start sites within 100-600 bp of one another. (The start sites of transcripts on the reverse strand were taken as ENSEMBL's 'transcript end' position). Putative bidirectional promoter sequences were retrieved from ENSMBL plant 17 chromosomes and searched for the presence of the CACGTG motif.

We used the AtGenExpress Visualisation Tool (AVT; http://jsp.weigelworld.org/expviz/expviz.jsp) to extract gene expression data where indicated using the datasets for development, abiotic stress, hormones and light [38-40].

\section{Sequence analysis}

Homologous sequences to genes At3g03150 and At3g03160 were identified using standard BLAST searching tools (http://www.ncbi.nlm.nih.gov/BLAST/). The Accession numbers of homologous sequences used for amino acid alignments are shown in Additional file 2: Table S1). Alignments were done using CLUSTALX and BioEdit [41,42]. Localisation prediction programs used were PSORT [43] and TargetP [44]. Searches for promoter motifs were done using PLACE [45] and transmembrane prediction was performed using the TMHMM Server v2.0 [46].

\section{Plant material and growth conditions}

Arabidopsis thaliana wild-type (Col-0) and T-DNA insertion plants were grown in a control environment with a $16 \mathrm{~h}$ photoperiod, $120-140 \mu \mathrm{mol} / \mathrm{m}^{2} / \mathrm{sec}$ light intensity, $40-50 \%$ relative humidity and a temperature of $21 \pm$ 
$2^{\circ} \mathrm{C}$. For crosses with dehiscent anthers, closed flower buds were emasculated 48-72 h before pollination.

For silique analysis, the five longest green siliques were collected from each plant (wild-type, T-DNA insertion line or cross between the two), opened under a dissecting microscope and the number of normal seeds, early and late aborted seeds as well as unfertilized ovules was determined.

\section{Stress treatments}

Arabidopsis seedlings were grown vertically for three weeks at $22^{\circ} \mathrm{C}$ on a medium containing $0.5 x M S$ salts, 0.5xMS vitamins, $0.5 \mathrm{gl}^{-1}$ 4-morpholineethanesulfonic acid (MES), 0.5\% (w/v) sucrose and 0.7\% agar, $\mathrm{pH} 5.7$. For each treatment seedlings were transferred into a petri dish with a sterile filter paper that was soaked in either liquid MS medium, $10 \mu \mathrm{M}$ ABA in $0.1 \%$ methanol or $0.1 \%$ methanol. Three seedlings from each treatment were collected for further analysis after $3 \mathrm{~h}$ and $24 \mathrm{~h}$. For the dehydration stress, seedlings were left in an open petri dish at room temperature for $1.5 \mathrm{~h}$. Primers for the KIN1 and RD29 genes were taken from Kim et al. [47].

\section{Protein localization}

The full-length coding region of At3g03150 was amplified from the SALK ORF-trimmed pUNI clone (u23027) with Gateway compatible primers and cloned into a pDONR207 entry vector (Invitrogen). This was used to make a C-terminal GFP fusion in GFP-C-BIN and subsequent transient transformation of tobacco cells. Tobacco leaves (Nicotiana benthamiana) were infiltrated with a solution of saturated Agrobacterium resuspended in $10 \mathrm{mM} \mathrm{MgCl} 2,10 \mathrm{mM} \mathrm{MES}, 100 \mu \mathrm{M}$ acetosyringone to $\mathrm{OD}_{600}$ 0.4) and observed for GFP localisation 10 days after infiltration. Mitochondria tracker CMX Ros red (Molecular Bioprobe) was used at $400 \mathrm{nM}$ in water for $45 \mathrm{~min}$ and washed 3 times for $5 \mathrm{~min}$ in water. Observation was carried out on an inverted SP2 confocal (Leica) using a 40x oil immersion lens. Sequential scans were taken with GFP excited at $488 \mathrm{~nm}$ with an Argon Ion laser and the Mito tracker at $543 \mathrm{~nm}$ from a green helium neon laser.

\section{Transcript analysis by RT-PCR and qRT-PCR}

Total RNA was extracted from the flower tissues of insertion lines and from flower, silique, root, rosette and cauline leaf and stem tissues of wild-type Arabidopsis and cDNA was made using the BioScript kit (Bioline) following the manufacturer's instructions. Primers for amplification of At3g03150 from cDNA were $150 \mathrm{~F}$ and $\mathrm{R}$; for At3g03160, $160 \mathrm{~F}$ and R; for At5g17165, $165 \mathrm{~F}$ and $\mathrm{R}$ and for At5g17190, $190 \mathrm{~F}$ and R. Actin was used as control using primers Actin2F and Actin2R.

Total RNA was extracted from ABA/stress treated seedlings of $A$. thaliana using TriSure ${ }^{\mathrm{TM}}$ (Bioline) and treated with DNase I (NEB), according to the manufacturer's instructions. $700 \mathrm{ng}$ of RNA from each sample were used in a $20 \mu \mathrm{l}$ cDNA synthesis reaction with the Tetro cDNA Synthesis Kit (Bioline), following the manufacturer's instructions. Quantification of At3g03150 and At3g03160 transcript levels by real-time PCR was performed using $1 \mathrm{ul}$ of a 1:20 dilution of cDNA template in a $20 \mathrm{ul}$ reaction containing SYBR Green JumpStart ${ }^{\mathrm{Tm}}$ Taq ReadyMix $^{\mathrm{TM}}$ (Sigma-Aldrich) and primers $150 \mathrm{qF}$ and $150 \mathrm{qR}$, or $160 \mathrm{qF}$ and $160 \mathrm{qR}$ at a final concentration of $0.5 \mathrm{uM}$. Each reaction was performed in triplicate in a PTC-200 Peltier thermal cycler (MJ Research) using the following conditions: denaturation at $95^{\circ} \mathrm{C}$ for $3 \mathrm{~min}$ followed by 40 cycles of denaturation at $95^{\circ} \mathrm{C}$ for $30 \mathrm{sec}$, annealing at $55^{\circ} \mathrm{C}$ for $30 \mathrm{sec}$ and extension at $72^{\circ} \mathrm{C}$ for $30 \mathrm{sec} .18 \mathrm{~S}$ was used the reference gene with primers $18 \mathrm{~S} F$ and 18S R All primers are listed in Additional file 3: Table S2.

\section{Promoter cloning}

The At3g03150-At3g03160 promoter sequence (between the two ATG start codons) was amplified from Col-0 genomic DNA using primers AtPromF and AtPromR (Additional file 3: Table S2) and a proofreading DNA polymerase (Velocity, Bioline). The amplified genomic fragment was then cloned into PJET1.2 vector using the CloneJET PCR Cloning Kit (Thermo Scientific) and confirmed by sequencing. The promoter fragment was amplified from pJET1.2 vector in both orientations using primers with suitable attB sites attached to them and cloned into Gateway ${ }^{\oplus}$ entry vector pDONR221 (Invitrogen). The primers used were 150promF and $\mathrm{R}$ for At3g03150 160promF and R for At3g03160. Each promoter entry clone was introduced into pKGWFS7 destination vector using single site recombination, in order to access the ability of the intergenic region to drive GUS expression in both orientations.

\section{Plant transformation}

Arabidopsis Col-0 plants were transformed with Agrobacterium tumefaciens GV3101 strain harboring either one of the two promoter-pKGWFS7 plasmids using a standard floral dipping method [48]. T1 seed collected from the transformed plants was plated on kanamycin selection plates. Surviving seedlings were transferred to soil and used for further analysis.

\section{GUS staining}

Siliques were harvested at stages just after fertilisation and up to endosperm cellularistion, fixed in $90 \%$ acetone at $-20^{\circ} \mathrm{C}$, infiltrated (under vacuum for 1 mintue) with GUS staining solution $\left(50 \mathrm{mM} \quad \mathrm{Na}_{2} \mathrm{HPO}_{4}, 50 \mathrm{mM}\right.$ $\mathrm{NaH}_{2} \mathrm{PO}_{4}, \mathrm{pH}$ 7.0, $2 \mathrm{mM}$ potassium ferricyanide, $2 \mathrm{mM}$ potassium ferrocyanide, $2 \mathrm{mM}$ EDTA, $1 \mathrm{mg} / \mathrm{ml} \mathrm{X-Gluc)}$ and incubated at $37^{\circ} \mathrm{C}$ for overnight. The same staining 
solution was used to infiltrate fresh tissues of seedlings, leaves and inflorescences. After staining, tissue was cleared with $70 \%$ ethanol and stored at $4^{\circ} \mathrm{C}$.

\section{Microscopy}

GUS-stained ovules and ovules for phenotypic analyses were mounted in chloral hydrate and analysed with DIC optics as described in Boisnard-Lorig et al., [49]. Images were captured using a digital camera and assembled with Adobe Photoshop software (Adobe Systems, Mountain View, CA).

\section{Insertion lines characterization}

SALK T-DNA lines SALK_121507 and SALK_025090 [50] were obtained through NASC (Nottingham Arabidopsis Stock Centre) and genotyped by PCR as recommended using the LBb1.3 primer and gene specific primers 507 F and R; 262 F and R (Additional file 3: Table S2).

\section{Genetic transmission through male and female gametes} In order to determine the gametophytic transmission efficiency (TE) of the T-DNA, reciprocal crosses between wild-type Col-0 and SALK_121507 or SALK_025090 plants were performed. Seed was collected from individual siliques and the F1 generation was screened for the presence of the T-DNA insertion. The TE through each gamete $\left(\mathrm{TE}_{\mathrm{MALE}}\right.$ and $\left.\mathrm{TE}_{\mathrm{FEMALE}}\right)$ was calculated according to Howden et al. [51].

\section{Pollen analyses}

Pollen of wild-type and T-DNA insertion lines was stained with DAPI (4',6-diamidino-2-phenylindole; $1 \mathrm{mg} / \mathrm{ml})$ and examined for any morphological differences. FDA (fluorescein diacetate) staining was used to access viability (10\% solution in acetone/0.3 M mannitol). Pollen germination assays were performed according to Boavida and McCormick [52].

\section{Results}

Identifying putative ABA-regulated/seed-expressed bidirectional promoters in Arabidopsis

We performed a promoter cis-element bioinformatics search based on specific examples of bidirectional gene pairs involved in aspects of seed biology [20,21,30, $31,33,34,36]$. We identified putative bidirectional promoters of 100-600 bp between predicted TSS (transcription start sites) of protein-coding genes in the Arabidopsis genome and further selected for those containing multiple (two or more) CACGTG motifs. This results in a list of 70 gene pairs (Table 1). The G-box ABRE is often found in combination with other motifs, coupling elements (CE) that can be based on or distinct from the G-box and also involved in the seed/ABA regulation. Therefore we searched PLACE [45] with all 70 intergenic regions focusing on DREs based on the CCGAC core and CE3s not derived from the ACGT core. Where these elements were also identified is indicated in Table 1.

The cellular localisation of each gene product was noted based on predictions using the TargetP tool and individual gene profiles available on TAIR. Proteins are predicted to lie in all main cell compartments and divergent gene pairs could be in the same or different locations. However, $25 \%$ were predicted to be localized to the plastid, $20 \%$ to the endomembrane/secretory system, $14 \%$ to the mitochondria and the remaining $40 \%$ to other components including cytoplasm and nucleus. At the functional or activity level, 33\% encode enzymes. Previous studies have noted an enrichment for enzymes/ metabolism and organellar localisation in the human genome [53,54] and the seed development process is naturally accompanied by extensive metabolic fluctuation $[33,55,56]$. $24 \%$ of genes are potentially involved in direct gene expression regulation, DNA/RNA binding and processing. Some of the genes identified have already been shown to be involved in embryo/endosperm development (At1g04630 and At2g20490 were identified as MEE4 and EDA27, respectively, by Pagnussat et al. [57] and other genes are more obviously associated with some form of light-regulation (At4g21280, $P s b Q$ subunit) [58]. Interestingly, MEE4 shares its bidirectional promoter with AtPOP5 which was shown to physically interact with AtPP30, involved in female gametophyte development, in an RNase P/MRP complex [59]. The TORMOZ and AURORA genes (At5g16750 and At2g25880) are involved in embryo development [60,61]; SYN1 (At5g05490) is essential for meiosis [62]; SD3 and DWF5 are membrane proteins involved in seedling development $[63,64]$. Other genes have been shown experimentally to be responsive to drought or ABA such as LEA4-1 and OEP16-S (At1g32560 and At4g16160; [33,65]; Additional file 1: Figure S2B and Additional file 1: Figure S1A). The gene pairs were also examined for the extent of co-expression using AtGenExpress Visualisation Tool [38-40] which showed that while in some cases the genes showed very similar patterns of expression, there were also cases where the expression patterns of both genes differed significantly in terms of both temporal and spatial patterns and also in terms of their response to various stresses (Additional file 1: Figure S2). Several parameters can be taken into account when assessing if a gene pairs' products might be directly linked functionally such as the extent of coexpression and the subcellular co-localization of the gene pair products. Only three gene pairs have products that are predicted to be targeted to the same organelle (not counting cytosolic predictions). At1g52230 and At1g52220, encoding the PSI subunit $\mathrm{H}$ and an unknown 
Table 1 Putative bidirectional gene pairs identified with 100-600 bp between transcription start sites (TSS) and containing at least two G-Box elements

\begin{tabular}{|c|c|c|c|c|c|c|c|c|}
\hline FWgene & RVgene & len & DRE & CE3 & FWgene annotation & RVgene annotation & FWlocation & RVlocation \\
\hline AT1G04635 & AT1G04630 & 202 & $\mathrm{y}$ & & AtPOP5 & maternal effect embryo arrest 4 (MEE4) & nucleolus & mitochondrion \\
\hline AT1G07510 & AT1G07500 & 347 & & & FtsH10 protease & unknown protein & mitochondrion & cytosol \\
\hline AT1G07660 & AT1G07645 & 452 & & & Histone superfamily & vicinal oxygen chelate (VOC) metalloenzyme & nucleus & cytosol \\
\hline AT1G07985 & AT1G07980 & 478 & & & Expressed protein & nuclear factor $\mathrm{Y}$, subunit $\mathrm{C} 10$ & nucleus & plastid \\
\hline AT1G15330 & AT1G15320 & 333 & & & Cystathionine beta-synthase (CBS) & unknown protein & cytosol & extracellular \\
\hline AT1G16740 & AT1G16730 & 378 & & & Ribosomal protein L20 & unknown protein 6 (UP6) & mitochondrion & nucleus \\
\hline AT1G19980 & AT1G19970 & 327 & & & cytomatrix protein-related & ER lumen protein retaining receptor family & nucleus & ER \\
\hline AT1G28540 & AT1G28530 & 164 & & & unknown protein & unknown protein & cytosol & plastid \\
\hline AT1G31420 & AT1G31410 & 259 & $\mathrm{y}$ & & LRR kinase (FEl1) & putrescine-binding transporter protein & membrane & plastid \\
\hline AT1G32560 & AT1G32550 & 367 & y & & LEA4-1 & Ferredoxin C2 & nucleus & plastid \\
\hline AT1G48840 & AT1G48830 & 264 & y & & unknown function (DUF639) & Ribosomal protein S7e family & membrane & cytosol \\
\hline AT1G50440 & AT1G50430 & 161 & & & RING/FYVE/PHD zinc finger & DWARF 5 (DWF5) -STEROL DELTA7 REDUCTASE & nucleus & membrane \\
\hline AT1G52230 & AT1G52220 & 139 & & & PHOTOSYSTEM I SUBUNIT H2 & unknown protein & plastid & plastid \\
\hline AT1G54870 & AT1G54860 & 375 & & & ChIADR aldehyde reductase & Glycoprotein membrane GPI-anchored & cytosol & extracellular \\
\hline AT1G56170 & AT1G56165 & 391 & & & CCAAT motif binding complex & non-coding RNA & nucleus & cytosol \\
\hline AT1G61790 & AT1G61780 & 237 & & & Oligosaccharyltransferase & postsynaptic protein-related & ER & nucleus \\
\hline AT1G65140 & AT1G65130 & 595 & & & Ubiquitin c-terminal hydrolase & Ubiquitin c-terminal hydrolase & cytosol & nucleus \\
\hline AT1G71090 & AT1G71080 & 370 & & & Auxin efflux carrier & RNA pol II transcription elongation factor & membrane & nucleus \\
\hline AT1G72030 & AT1G72020 & 434 & & & Acyl-CoA N-acyltransferase & unknown protein & plastid & mitochondrion \\
\hline AT1G77370 & AT1G77360 & 307 & & & Glutaredoxin & Tetratricopeptide repeat (TPR)-like & extracellular & mitochondrion \\
\hline AT2G20490 & AT2G20480 & 189 & & & NOP10; EDA27 (RNA binding) & unknown protein & nucleolus & nucleus \\
\hline AT2G25890 & AT2G25880 & 470 & & & Oleosin & Ser/Thr kinases - Ataurora2 (AUR2) & lipid body & nucleus \\
\hline AT2G29560 & AT2G29550 & 523 & & & phosphoenolpyruvate enolase & beta-tubulin (TUB7) & cytosol & nucleus \\
\hline AT2G38040 & AT2G38025 & 385 & y & & acetyl-CoA carboxylase subunit & Cysteine proteinase superfamily & plastid & plastid \\
\hline AT2G38660 & AT2G38650 & 183 & & & Amino acid dehydrogenase & galacturonosyltransferase 7 (GAUT7) & mitochondrion & golgi \\
\hline AT2G39460 & AT2G39450 & 331 & y & & $60 S$ ribosomal protein L23aA & manganese transporter & cytosol & golgi \\
\hline АT2G43190 & AT2G43180 & 187 & & & AtPOP4 (RNA processing) & Phosphoenolpyruvate carboxylase family & nucleolus & plastid \\
\hline AT2G45740 & AT2G45730 & 556 & y & & peroxin11 (PEX11) family & eukaryotic initiation factor $3 \otimes$ subunit & peroxisome & cytosol \\
\hline AT3G03160 & АТ3G03150 & 264 & y & y & unknown protein & unknown protein & endomembrane & mitochondrion \\
\hline AT3G03320 & AT3G03310 & 135 & & & RNA-binding protein & lecithin:cholesterol acyltransferase 3 & cytosol & plasma membrane \\
\hline AT3G12320 & AT3G12300 & 580 & y & & unknown protein & unknown protein & nucleus & cytosol \\
\hline AT3G13190 & AT3G13180 & 559 & & & unknown function (DUF827) & rRNA small subunit methyltransferase B & nucleus & plastid \\
\hline AT3G14340 & AT3G14330 & 305 & & & unknown protein & Tetratricopeptide repeat (TPR)-like & membrane & mitochondrion \\
\hline AT3G15290 & AT3G15280 & 304 & & & 3-hydroxyacyl-CoA DH & unknown protein & peroxisome & mitochondrion \\
\hline AT3G16010 & AT3G16000 & 197 & & & PPR-like superfamily & plastid DNA-binding protein; MFP1 & mitochondrion & plastid \\
\hline AT3G18215 & AT3G18210 & 245 & & & unknown function, DUF599 & $2 \mathrm{OG}$ and $\mathrm{Fe}(\mathrm{II})$-dependent oxygenase & membrane & nucleus \\
\hline
\end{tabular}


Table 1 Putative bidirectional gene pairs identified with 100-600 bp between transcription start sites (TSS) and containing at least two G-Box elements

(Continued)

\begin{tabular}{|c|c|c|c|c|c|c|c|}
\hline AT3G26618 & AT3G26616 & 464 & & eukaryotic release factor 1-3 & unknown protein & cytosol & cytosol \\
\hline AT3G52230 & AT3G52220 & 139 & & unknown protein & Kinase phosphorylation domain & plastid & nucleus \\
\hline AT3G53180 & AT3G53170 & 477 & & glutamate-ammonia ligases & Tetratricopeptide repeat (TPR)-like & cytosol & cytosol \\
\hline AT3G59500 & AT3G59490 & 190 & & HRF1 family protein & unknown protein & ER membrane & nucleus \\
\hline AT4G00030 & AT4G00026 & 168 & & Plastid-lipid associated (PAP) & SD3 (Segregation Distortion 3); TIM21 & plastid & mitochondrion \\
\hline AT4G01270 & AT4G01265 & 577 & y & RING/U-box superfamily & raffinose synthase family pseudogene & nucleus & NA \\
\hline AT4G02430 & AT4G02425 & 189 & y & S/R-Rich Protein Splicing Factors & unknown protein & nucleus & nucleus \\
\hline AT4G11985 & AT4G11980 & 129 & & pre-tRNA/non-coding RNA & nudix hydrolase homolog 14 & nucleus/cytosol & plastid \\
\hline AT4G16160 & AT4G16155 & 205 & y & OEP16-S & dihydrolipoyl dehydrogenase & plastid & plastid \\
\hline AT4G17560 & AT4G17550 & 541 & y & Ribosomal protein L19 family & glycerol-3-phosphate permease gene family & plastid & mitochondrion \\
\hline AT4G17730 & AT4G17720 & 440 & & syntaxin 23 & RNA-binding (RRM/RBD/RNP motifs) family & cytosol & cytosol \\
\hline AT4G18240 & AT4G18230 & 169 & & starch synthase 4 (SS4) & unknown protein & plastid & plasma membrane \\
\hline AT4G18370 & AT4G18360 & 447 & & DEG5 - photosystem II repair & Aldolase-type TIM barrel family & plastid & peroxisome \\
\hline AT4G19020 & AT4G19010 & 277 & & chromomethylase 2 (CMT2) & AMP-dependent synthetase and ligase family & nucleus & peroxisome \\
\hline AT4G21280 & AT4G21270 & 267 & & PsbQ subunit photosystem II & kinesin-like motor protein & plastid & nucleus \\
\hline AT4G23840 & AT4G23820 & 254 & & Leucine-rich repeat (LRR) family & Pectin lyase-like superfamily & cytosol & extracellular \\
\hline AT4G25140 & AT4G25130 & 366 & & Oleosin1 & chloroplast methionine sulfoxide reductase & lipid body & plastid \\
\hline AT4G25580 & AT4G25570 & 561 & & cold acclimation protein (CAP160) & cytochrome b561 & nucleus & plasma membrane \\
\hline AT4G31080 & AT4G31070 & 351 & & unknown function (DUF2296) & Tetratricopeptide repeat (TPR)-like & ER & cytosol \\
\hline AT4G33540 & AT4G33530 & 365 & & metallo-beta-lactamase family & K + UPTAKE PERMEASE 5 (KUP5) & plastid & plasma membrane \\
\hline AT5G05490 & AT5G05480 & 293 & & SYN1 (RAD21-like) gene & Peptide-N4-asparagine amidase A protein & nucleus & plasma membrane \\
\hline AT5G05987 & AT5G05980 & 509 & y & prenylated RAB acceptor $1 . A 2$ & folylpolyglutamate synthetase isoform & membrane & mitochondrion \\
\hline AT5G07320 & AT5G07315 & 363 & & Mito ATP-Mg/Pi transporter & pre-tRNA/non-coding RNA & mitochondrion & nucleus/cytosol \\
\hline AT5G10080 & AT5G10070 & 409 & & Eukaryotic aspartyl protease & RNase $L$ inhibitor protein-related & membrane & cytosol \\
\hline AT5G10745 & AT5G10740 & 275 & & unknown protein & Protein phosphatase $2 \mathrm{C}$ family protein & membrane & nucleus \\
\hline AT5G16760 & AT5G16750 & 331 & & inositol-trisphosphate 5/6-kinase & TORMOZEMBRYO DEFECTIVE (TOZ) & cytosol & nucleolus \\
\hline AT5G37350 & AT5G37340 & 232 & & RIO1 kinase & ZPR1 zinc-finger domain protein & nucleus & cytosol \\
\hline AT5G51540 & AT5G51530 & 529 & & Zincin-like metalloproteases & Ubiquitin c-terminal hydrolase & plastid & cytosol \\
\hline AT5G54062 & AT5G54060 & 424 & & unknown protein & anthocyanin 3-O-glucoside & extracellular & membrane \\
\hline AT5G54970 & AT5G54960 & 449 & & unknown protein & pyruvate decarboxylase-2 & cytosol & cytosol \\
\hline AT5G61940 & AT5G61930 & 481 & y & Ubiquitin c-terminal hydrolase & ACCUMULATION OF PHOTOSYSTEM ONE 3 & nucleus & mitochondrion \\
\hline AT5G62490 & AT5G62480 & 537 & & AtHVA22 family & glutathione transferase & extracellular & cytosol \\
\hline AT5G64220 & AT5G64210 & 582 & & Calmodulin-binding activator & isoform of alternative oxidase & nucleus & mitochondrion \\
\hline AT5G67230 & AT5G67220 & 514 & & GT43 glycosyltransferase family & FMN-linked oxidoreductase superfamily & mitochondrion & mitochondrion \\
\hline
\end{tabular}

of DRE and/or CE3 motif (not derived from an ACGT-core sequence) also indicated by ' $y$ '.

The only gene pair with a DRE and a CE3 element is highlighted. 
protein respectively, have identical expression patterns according to AtGenExpress (Additional file 1: Figure S2A) and are localized in the thylakoid system of the plastid. Furthermore we found that a previous analyses of a chloroplast protein interaction network [66] had predicted an interaction between these proteins and that the localization of the unknown At1g52220 product to the thylakoid was confirmed as well as a physical interaction with the D subunit of PSI.

CE3 coupling elements are rare in the Arabidopsis genome [26,67] and while CE3-like elements have been described $[47,68]$, this is the first report of a consensus CE3 element in Arabidopsis. Therefore we chose to focus on the only pair of genes containing both a DRE and a CE3 element (Highlighted in Table 1). In addition, this pair At3g03150-At3g03160 has SALK T-DNA insertion lines available within the coding regions to enable preliminary functional analyses of the genes.

\section{At3g03150 and At3g03160 are transcribed from a putative bidirectional promoter and encode novel plant-specific proteins}

Analysis of the promoter region revealed that divergent ORFs (At3g03150 and At3g03160) are separated by
$518 \mathrm{bp}$, suggesting that both genes possibly share the same promoter and that expression may be co-regulated. The promoter contains several ACGT elements and a $100 \%$ match to the CE3 ABA responsive element in the HVA1 promoter of barley [69]; (Figure 1A).

The protein sequence of At3g03150 had no familiar domains or motifs that would indicate a function. Localization prediction using PSORT and TargetP programs indicated (with $75 \%$ and $91 \%$ probability, respectively) mitochondrial localization. The predicted cleavage site matches consensus sites and the targeting region is rich in serine. Overall the 120 amino acid protein is composed of almost $15 \%$ serine and threonine residues. Over $37 \%$ are PEST residues of which $16 \%$ are serine alone. A high PEST content is indicative of proteins with high turnover and indicates that the protein may be unstable. The gene's structure is particularly striking showing the presence of one intron of over $1.2 \mathrm{~kb}$ and with the first exon discretely encoding the target sequence. To test the validity of the localization prediction of At3g03150, a translational protein fusion with GFP at the C-terminal of the protein was constructed to test for mitochondrial localization. Results in Additional file 1: Figure S3A confirm localization of the protein to the mitochondrion.

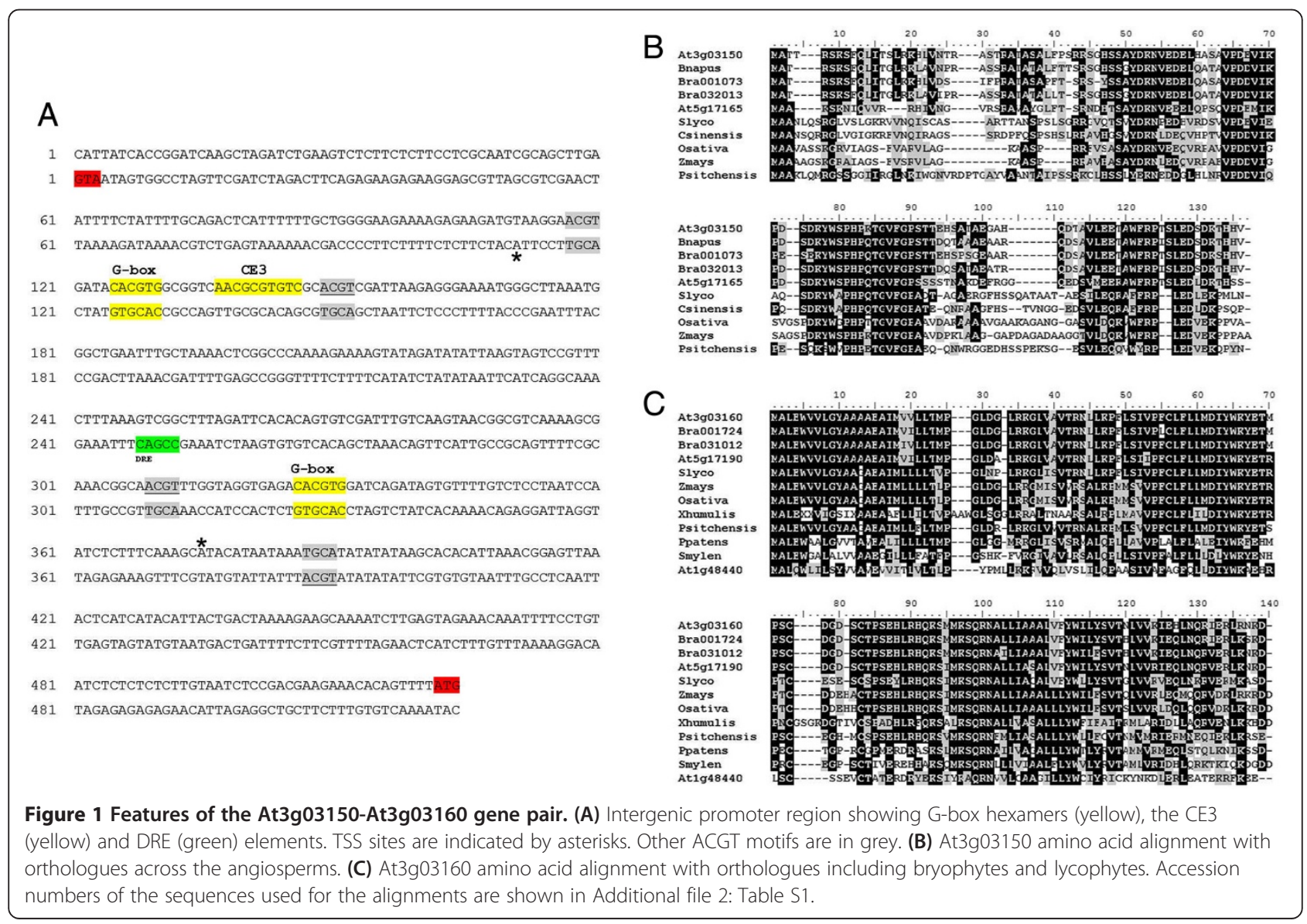


The divergent gene, At3g03160, is also of unknown function but contains three transmembrane domains (TMHMM Server v2.; [46]; Additional file 1: Figure S3B) and is homologous to a dehydration-induced transcript from the resurrection plant Xerophyta humilis [70] (Figure 1C). The intergenic promoter contains a consensus DRE (Figure 1A). TargetP predicts a signal peptide and so it is likely the protein is part of the secretory pathway.

In addition, there are orthologues of At3g03150 in vascular plants only while At3g03160 has orthologues in Selaginella and Physcomitrella patens (Figure 1B,C). The strong preservation of certain blocks of sequence between At3g03150 and orthologues identified in Genbank, even before the emergence of the flowering plants (represented by the pine sequence), suggests that these putative active sites are well-conserved across a broad evolutionary time-frame (Figure 1B). The level of amino acid identity between At3g03160 orthologues across the embryophyta (land plants) is striking (Figure 1C).

Both genes have paralogues on chromosome 5 and appear to be the result of a genomic duplication previously identified $[71,72]$. The corresponding region on chromosome 5 preserves the divergent arrangement of the genes but with two other genes, At5g17170 and At5g17180, intervening (Additional file 1: Figure S3C). These intervening genes are single-copy. At3g03160 is homologous to At5g17190. In the case of At5g17165, the modular nature of the gene structure with the first exon encoding the targeting peptide is maintained.

BLAST analysis against the rice and Brassica genomes revealed that the bidirectional arrangement of these two genes is only conserved in Brassica rapa. The duplication corresponding to At3g03160/At5g17190 and At3g03150/ At5g17165 occurred before Brassica/Arabidopsis split and

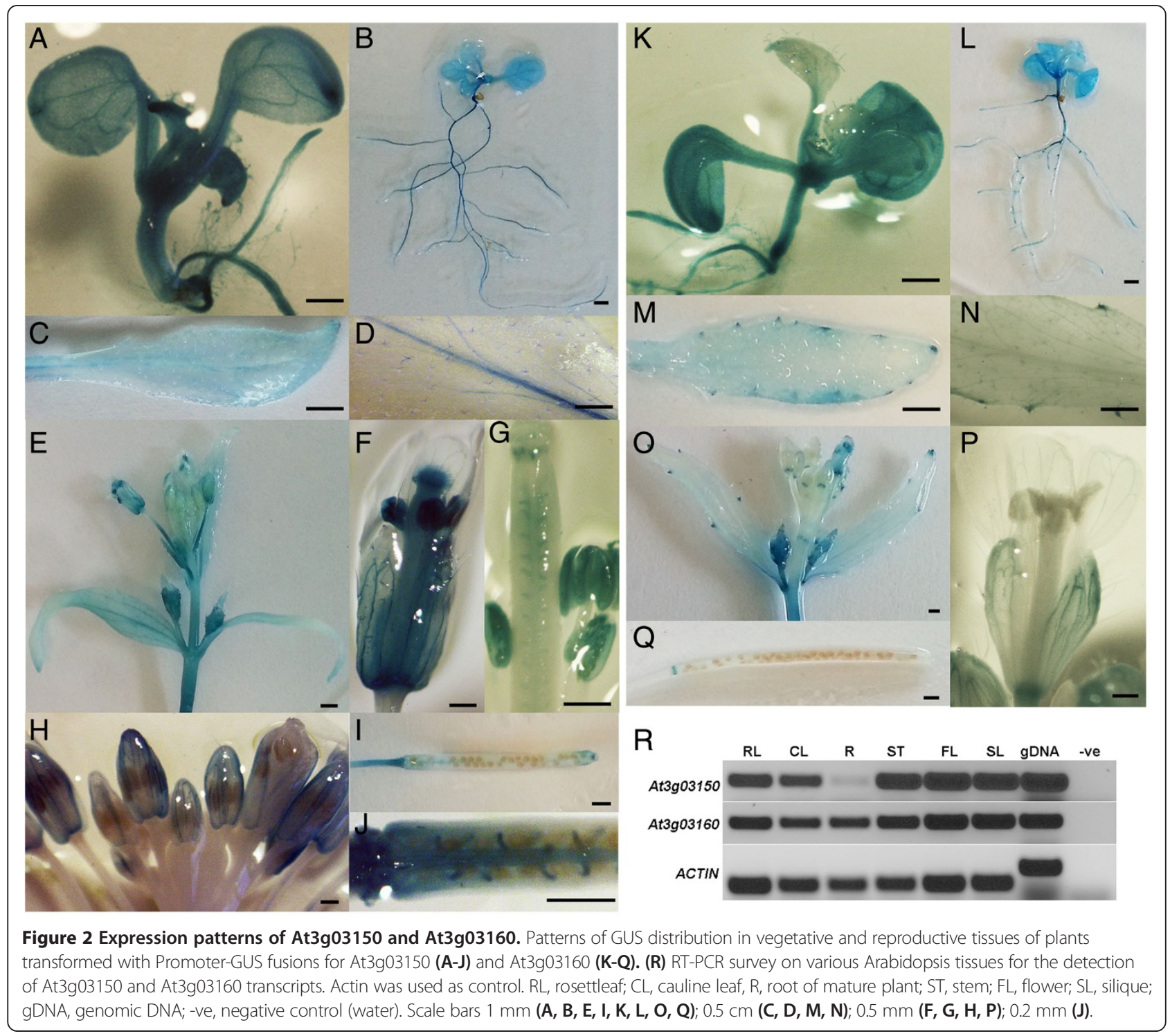


a further duplication in Brassica produced two At3g03150 and two At3g03160 paralogues (Figure 1B,C).

\section{Both genes share a similar general expression pattern but} are not identical

A general RT-PCR survey suggested that both genes were transcribed in similar spatial patterns (Figure 2R) and Yang et al. [73] had previously listed these genes as being co-expressed divergent genes. However, data from AtGenExpress revealed more subtle differences between the At3g03150-At3g03160 gene pair. Therefore, the intergenic promoter was used to make transcriptionfusions with the GUS reporter gene in both orientations and the expression pattern was monitored in detail (Figure 2). At the seedling stage, GUS expression in both orientations was high and ubiquitous though in older seedlings the expression of At3g03160 appeared to be more localized to the tips of the main and lateral roots and in the initiating lateral buds. In mature leaves the expression of At3g03150 was obvious in the vasculature while At3g03160 expression was very noticeable in the hydathodes. Both genes were expressed extensively in

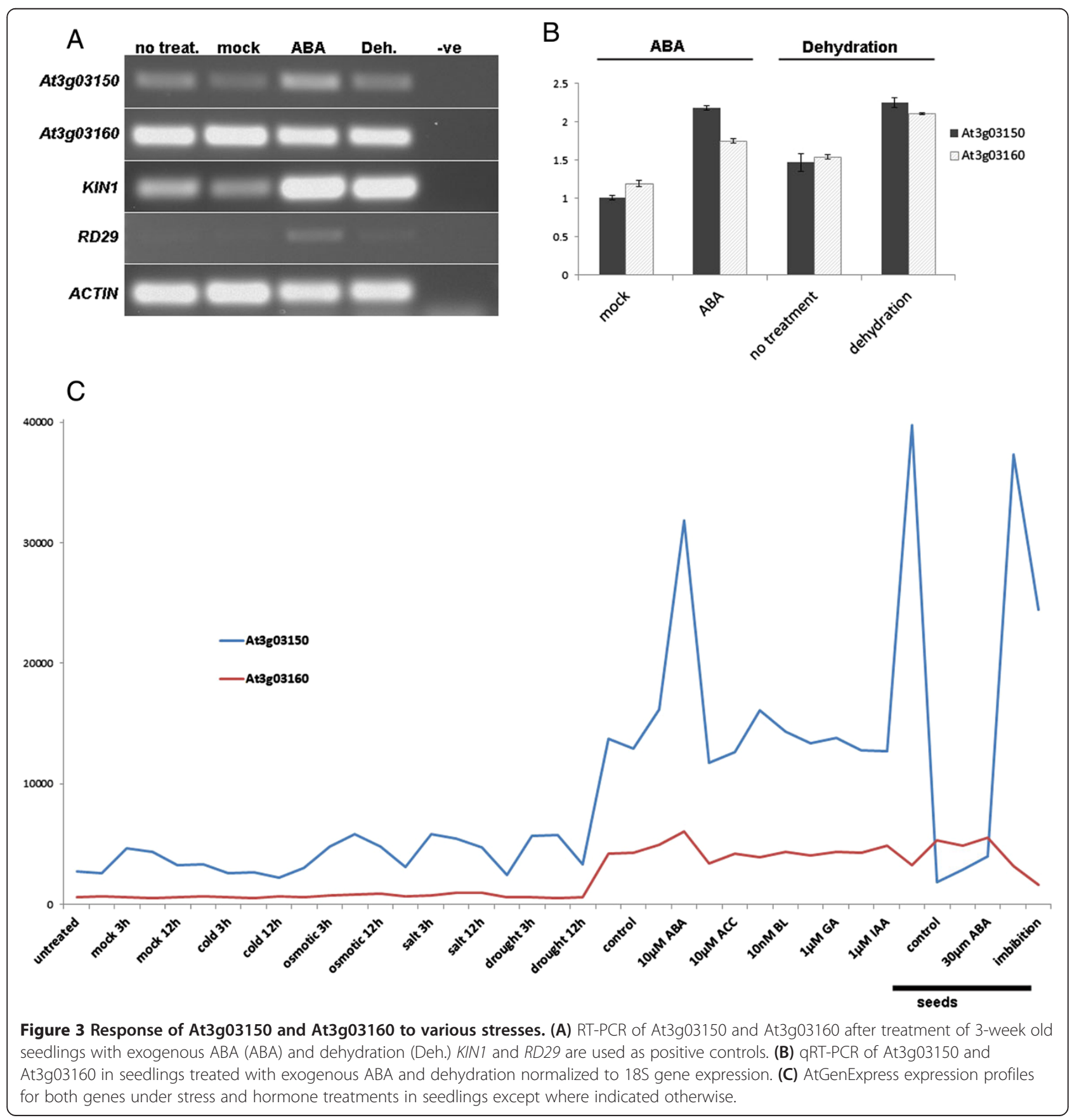


floral buds, open flower and fruit tissues but there was significant variation through development. Both genes were expressed in outer whorls early in development but At3g03160 became highly localized to the abscission zones and pedicel as the flower matured. Furthermore, expression in stigmatic tissues as well as in the anthers and pollen was much stronger in the At3g03150 orientation. There was also strikingly strong GUS expression observed in the funiculus in the At3g03150 orientation (Figure 2).

The expression patterns of the paralogues At5g17165 and At5g17190, respectively, were also checked by RTPCR with gene-specific primers. At5g17165 produced a transcript spanning the two exons which was detectable at a level significantly less than that of At3g03150 except in flower tissues (Additional file 1: Figure S3D). At5g17190, like At3g03160 is also highly expressed in roots and developing seeds (Additional file 1: Figure S3D).

\section{The genes respond differently to stresses}

The presence of consensus and adjacent ABRE and CE3 elements in the intergenic region strongly suggested that At3g03150 would be regulated by ABA. In addition, the AtGenExpress profile for At3g03150 also indicated that the gene is up-regulated in ABA experiments. To confirm this experimentally, expression of At3g03150 was examined by RT-PCR in 3-week old seedlings subjected to addition of exogenous ABA. Genes known to respond to ABA, KIN1 and RD29 were used as positive controls and Figure 3A shows that At3g03150 responded to ABA treatment. In contrast we did not detect any visible response of At3g03160 to ABA treatment nor any response to dehydration treatment using standard RT-PCR. We had expected to detect some response of At3g03160 to dehydration based on its homology to a drought induced transcript [70] and the presence of a putative DRE element in the promoter (Figure 1A). We therefore repeated the analyses using qRT-PCR (Figure 3B) on both genes normalized to the $18 \mathrm{~S}$ reference gene. This showed the ABA response already seen in At3g03150 but also indicated a weaker response from At3g03160. In addition, both genes were upregulated under dehydration.

Data pertaining to stress and hormone treatments was also extracted from AtGenExpress (Figure 3C). This showed obvious ABA responsiveness in At3g03150 but also a weaker response of At3g03160 at $10 \mu \mathrm{M}$ ABA. At3g03150 responded to drought treatments at 3 and 6 hours but no discernible response was seen for At3g03160 - however there is an obvious reduction in At3g03160 expression on seed imbibition suggesting that the gene may respond negatively to hydration in this context.

\section{Both genes play a role in seed development}

A homozygous SALK T-DNA insertion line (SALK_025090) was obtained for At3g03160 and analyzed. Genotyping and sequencing confirmed that the T-DNA insertion was located $119 \mathrm{bp}$ downstream of the start codon within the coding sequence and RT-PCR showed that there was no expression of the At3g03160 gene in this insertion line (Figure 4A). Expression of the adjacent divergent At5g03150 was also tested to make sure that the expression levels of this gene were not affected in the At3g03160 insertion line (Figure 4A). Phenotypic analysis revealed a significantly lower seed set in the siliques (Table 2, Figure 4B). Specifically, there was an increase in both the number of unfertilized ovules and aborted seeds.

SALK T-DNA lines were also obtained and analyzed for At3g03150. SALK_121507 was genotyped and sequenced and it was confirmed that the insertion was 3 bp downstream of the ATG codon - the only T-DNA line with an insert in the coding region of the gene (Figure 5A). This line could not be propagated as a homozygous line but the heterozygous lines segregated with a silique and ovule phenotype (Figure 5B-D). Siliques of the heterozygotes were shorter than wild-type. $58.21 \%$ of ovules appeared to be unfertilised (compared to $3.22 \%$ for the wild-type). A higher than normal percentage of late aborted seeds were also observed compared to the wild-type (6.97\%) (Table 2). Figure 5C shows the presence of large white ovules in the siliques of heterozygous plants adjacent to normal green ovules.

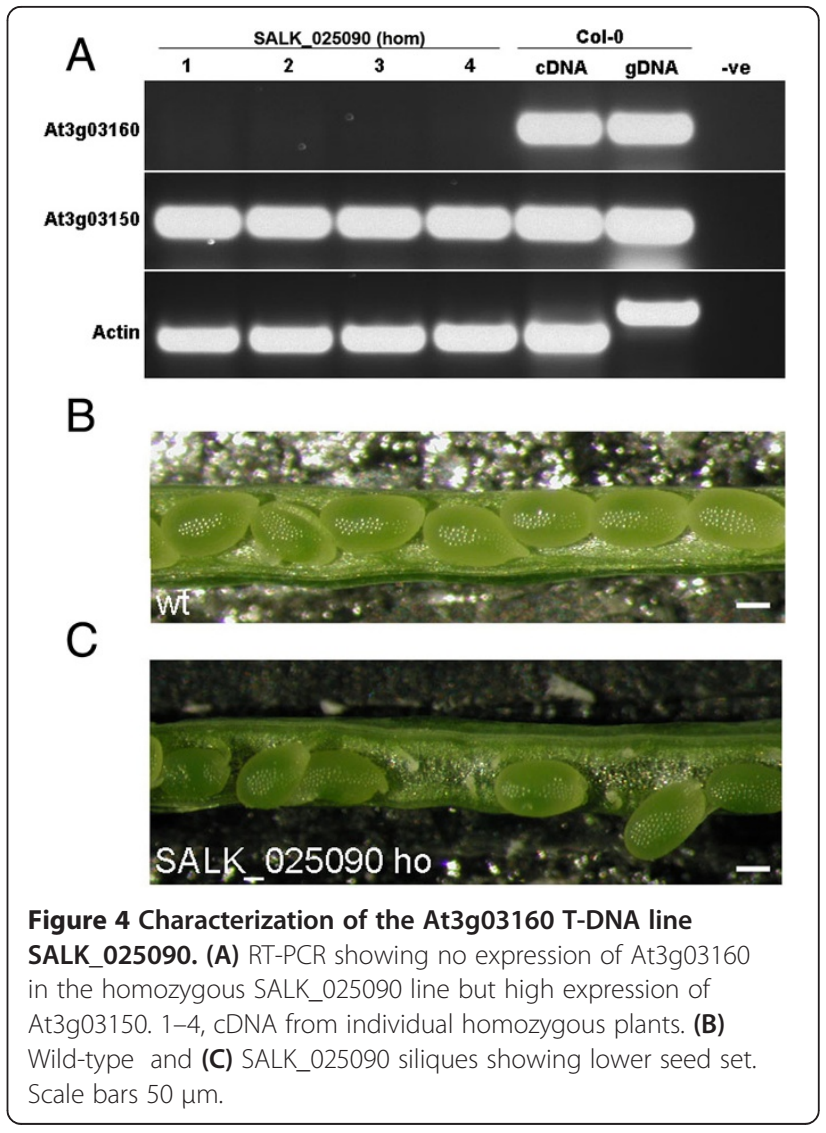


Table 2 Seed counts from siliques of wild-type Col-0 and T-DNA insertion lines for At3g03150 and At3g03160

\begin{tabular}{ccccc}
\hline Line & $\begin{array}{c}\text { \% Unfertilised } \\
\text { ovules }\end{array}$ & $\begin{array}{c}\text { \% Early } \\
\text { aborted } \\
\text { seeds }\end{array}$ & $\begin{array}{c}\text { \% Late } \\
\text { aborted } \\
\text { seeds }\end{array}$ & $\begin{array}{c}\text { \% Normal } \\
\text { dev. } \\
\text { seeds }\end{array}$ \\
\hline Col-0 & 3.22 & 0.63 & 0.58 & 95.56 \\
SALK_121507(het) & 58.21 & 0.63 & 6.97 & 34.19 \\
SALK_025090(hom) & 22.15 & 0.74 & 5.29 & 71.18 \\
\hline
\end{tabular}

Microscopic analysis of cleared samples showed that these ovules cease developing even before true globular stage (Figure 5D) when the adjacent ovules have developed to walking stick stage. There also appears to be a defect in endosperm development at the chalazal end. Maternal tissues appear to develop normally and the aberrant embryo and endosperm does not affect ovule growth and size. The presence of unfertilized ovules in both insertion lines prompted an analysis of pollen to determine if that might be contributing to the failure of fertilization. Pollen from the SALK_025090 homozygotes and the SALK_121507 heterozygotes stained with DAPI to assess grain morphology and FDA to check pollen grain viability, while pollen germination assays were also performed. The results suggest that the SALK_025090 pollen is normal when compared to wild-type but that the pollen of the SALK_121507 line is defective with a relatively high percentage (30\%) of collapsed and nongerminating pollen grains produced (Figure 6). This correlates with expression patterns of the genes as GUS expression was detected in pollen for the At3g03150 promoter only (Figure 2F,G).

Selfing of the SALK_121507 heterozygotes produced a consistent ratio of wild-type to heterozygote of 1:0.7 in progeny populations suggesting that it was a gametophytic mutant. This was tested further by crossing the heterozygote to wild-type plants as both pollen donor and recipient. Screening of the F1 population of the reciprocal out-crosses to the wild-type for the presence of the T-DNA insertion revealed that there is a slight reduction in the transmission efficiency both through the male and the female $\left(\mathrm{TE}_{\text {male }}=70.5 \%, \mathrm{TE}_{\text {female }}=88 \%\right.$, Additional file 4: Table S3). The fact that, despite the significant transmission through both gametophytes, homozygous plants for the T-DNA insertion were never recovered after selfing indicates that this mutation causes zygotic lethality.

\section{Discussion}

Though recognized as being a common phenomenon in animal and plant genomes based on bioinformatics

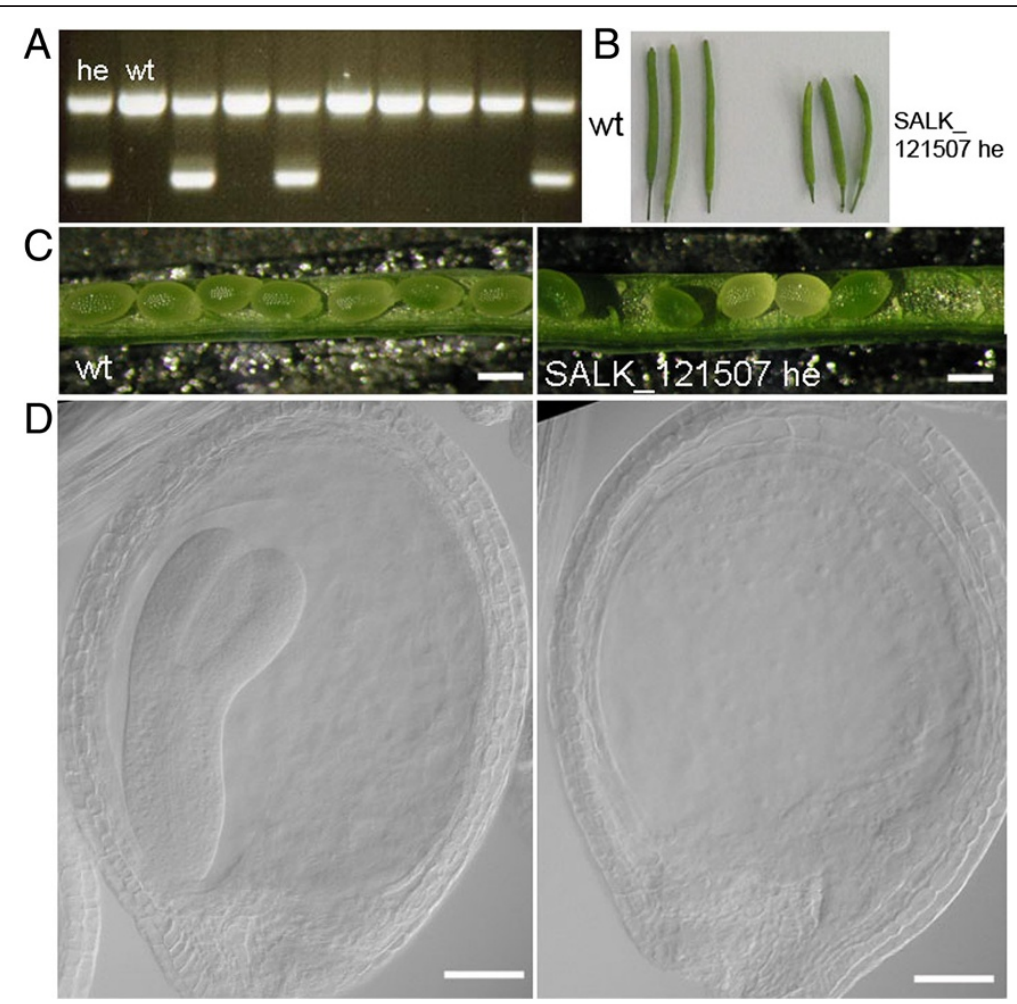

Figure 5 Characterization of the At3g03150 T-DNA line SALK_121507. (A) Genotyping of SALK-121507 showing identification of heterozygous (double bands) and wild-type plants (single bands). (B) Shorter siliques in heterozygous SALK_121507 plants compared to wild-type. (C) Unfertilisated ovules and late aborted seeds (white) in SALK_121507 compared to wild-type. (D) Cleared adjacent wild-type (left) and aborted seeds (right) in a SALK_121507 silique. Scale bars $100 \mu \mathrm{m}$ (C); 50 m (D). 

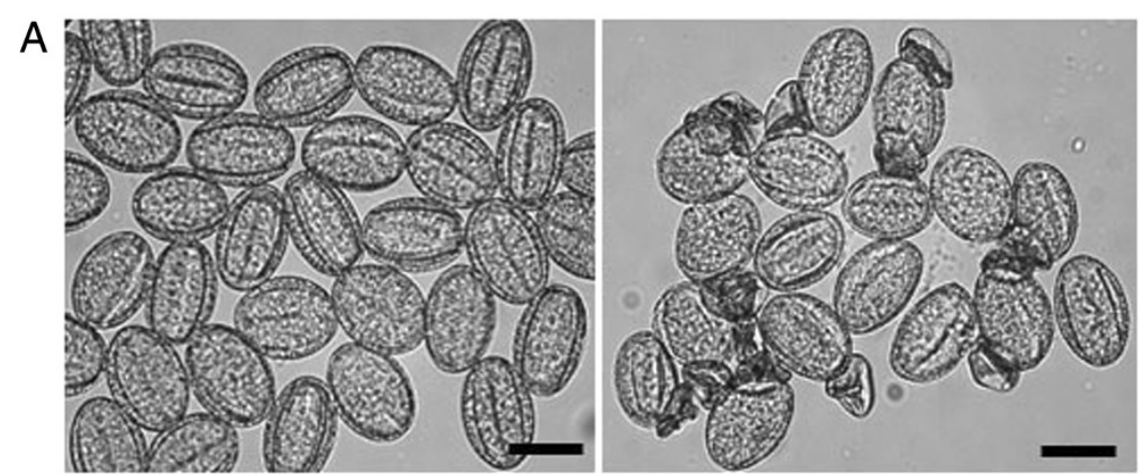

B

\% Collapsed Pollen

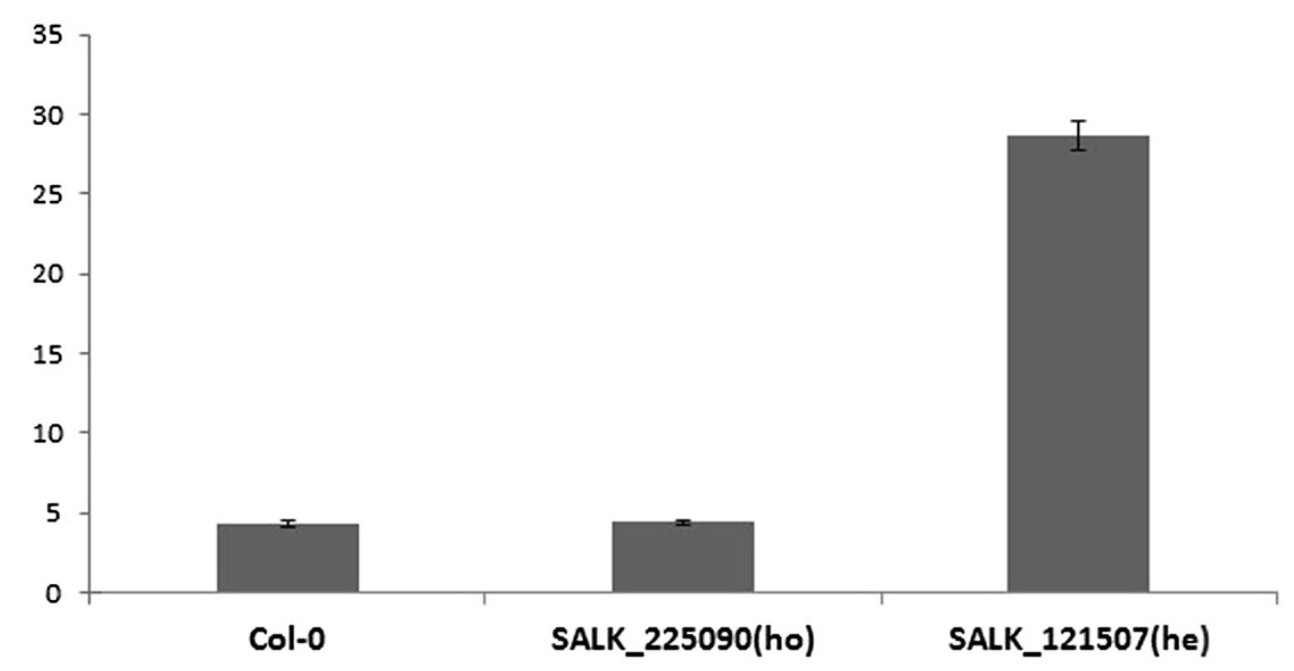

C

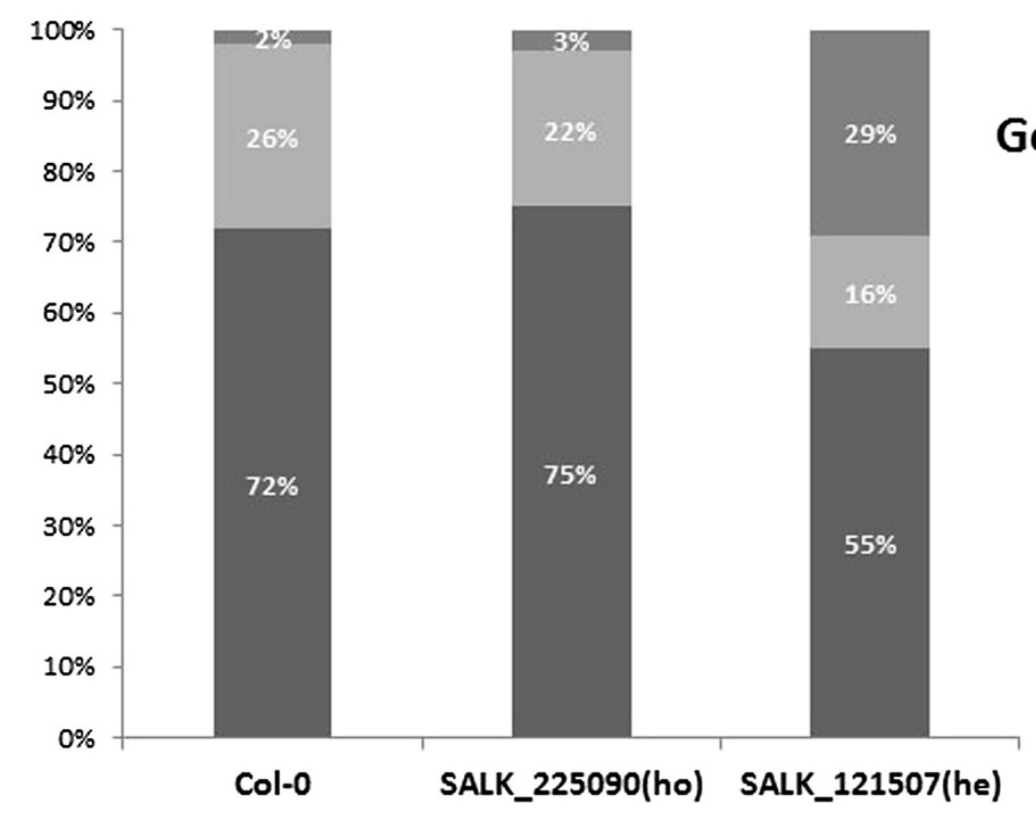

Collapsed

Not germinated

Germinated

Pollen Germination 
(See figure on previous page.)

Figure 6 Analyses of pollen in SALK_121507 heterozygote and SALK_025090 homozygote lines. (A) Comparison of wild-type (left) and SALK_121507 heterozygote pollen (right) showing a high percentage of collapsed pollen grains. Scale bars $20 \mu \mathrm{m}$. (B) Percentage of collapsed pollen in wild-type, SALK_025090 homozygous and SALK_121507 heterozygous lines. Error bars represent \pm SE. (C) Pollen germination assay highlighting the lower percentage of germinating pollen grains in heterozygous SALK_121507 lines compared to the wild-type and homozygous SALK_025090.

analyses, there is currently no example in the literature that uses a targeted analysis of bidirectional promoters with associated functional characterization of the genes involved. Here we have conducted a targeted search for putative bidirectional promoters involved in seed development using limited examples from the literature and characterized one of the promoters and associated gene pairs in detail, including preliminary functional analyses. This approach could complement conventional screening approaches in the search for genes involved in seedassociated processes [57,74-77] and/or for genes regulated by hormones and stresses [26] and our dataset contains some genes also identified in these screens $[26,57]$. The bidirectional promoter structure suggests co-ordination of expression and indeed much of the bioinformatics analysis to date includes evidence of co-expression of diverging genes based on the large volume of transcriptomic data available. AtGenExpress analysis of the 70 bimotif flanking genes shows some that mirror each other and others that are very different (Additional file 1: Figure S1; Additional file 5: File S1). Bioinformatics analyses have tended to focus on the co-expression or even common GO categorization. With the large datasets this is understandable but if focusing on specific subsets it might be possible to tease apart other cases where protein function or expression pattern is not obviously similar. Co-expression does not necessarily mean spatial and temporal expression similarities but could also involve a coordinated response to stress that could be tissue-distinct, and indeed even organelle -distinct. These coordinated responses may be mediated through promoter cis-elements. It has been found that by integrating known cis-elements with co-expression increases the reliability of associated gene function prediction [78]. Though $40 \%$ of the genes in Table 1 are predicted to be mitochondrial or plastid-localised, there are only three cases where both genes are predicted to be localized to the same organelle. In the case of the oleosin and PMSR genes, the AtGenExpress expression profiles diverge considerably with oleosin being seed-specific and PMSR expressed ubiquitously (Additional file 1: Figure S1B). In addition, oleosin is ABA-induced - often characteristic of a gene highly expressed in maturing seeds - while PMSR responds to oxidative stress, a natural consequence of seed maturation [36,56]. While the At3g03150-At3g03160 intergenic region contains two ABRE palindromic CACGTG hexamers, the adjacent nucleotides vary in either orientation (which has shown to be an important determinant of binding specificity; [24,25]) and the CE3 element is unidirectional. As might be expected therefore this variation is reflected in expression patterns and function, though both genes appear to affect aspects of seed development.

The bidirectional arrangement might be a particularly efficient way to mediate concerted or complementary response to stresses or environmental stimuli such as light or hormones. Bondino and Valle [12] pointed out that plants being sessile may need sophisticated means of coordinating gene expression responses to various stresses. In addition to the promoters coordinating responses to varied stresses and developmental signals, the localization of the gene products to varied organelles reflect a means of coordinating the intracellular interactions. Stresses such as drought, cold and salinity have shared and distinct signaling pathways, some of which are ABA-dependent [18]. In the case of At3g03150-At3g03160, the former is strongly regulated by $\mathrm{ABA}$ and located in the mitochondrion while the latter has a weaker response to $\mathrm{ABA}$ and is membrane-bound (though may be regulated by drought based on the presence of a DRE element and homology to a $X$. humilis desiccation-induced transcript) [70]. In the case of At1g07645 in Table 1 it is also homologous to a desiccation-induced $X$. humilis metalloenzyme but its expression was not affected in Arabidopsis seedlings under drought conditions [79]. Zhang et al. [26] searched for ABRE cis-elements in promoters to identify genes involved in associated stress responses but did not include any selection for potential bidirectionality in the promoters. Despite this, within the list of the top 40 predicted ABA/stress responsive genes in this study, 4 pairs of genes and another gene (23\%) are also on our list in Table 1 and a further two pairs of divergent genes are also included (these were not on our list because the distance was slightly larger between genes and the ABRE search was not restricted to the CACGTC motif).

Co-regulation or co-ordination of the expression of multiple genes has been described in other arrangements and contexts. Operon structures, once thought exclusive to prokaryotes, have been found in biosynthetic pathways in plants (summarized by DellaPenna and O' Conner [80]) coordinating the expression of genes with distinct functions but in a common biosynthetic pathway. Bidirectional promoters may constitute another means of coordinated expression in eukaryotes [53].

Analyses of the gene pairs spanning a putative bidirectional promoter may also help uncover functions for the vast array of unknown genes that remain to be characterised 
[53]. An initially "unknown" gene identified with a TSS $200 \mathrm{bp}$ upstream and divergent to the PARKIN gene (a ubiquitin E3 ligase determining aspects of parkinsonism), PACRG (PArkin Co-Regulated Gene; [81]), was shown to share a common molecular pathway [82]. We were intrigued to find that in the case of the At1g52230 and At1g52220 gene pair, encoding the PSI subunit $\mathrm{H}$ and an unknown protein respectively, identified here (Table 1), a previous construction of a chloroplast protein interaction network had predicted an interaction between these proteins and a physical interaction of At1g52220 with a PSI subunit was confirmed [66].

There are still thousands of genes for which there is no definitive function assigned and this can only be done by careful experimental examination of individual genes in the laboratory at multiple levels - gene sequence, expression and function. In the Arabidopsis genome at least 40\% of genes still have no determined function [83] and $20 \%$ of the mitochondrial proteome consisted of unknown proteins, many plant-specific [84]. Analyses of previously uncharacterised and plant-specific genes such as mitochondrial At3g13150 and transmembrane At3g03160 help accelerate these potential discoveries. Though we do not know what the activities of the encoded proteins are, we have described preliminary evidence of a common involvement in aspects of seed development.

\section{Conclusions}

Bidirectional promoters are common in genome sequence but understudied experimentally, particularly in plants. Focusing on the G-box promoter motif, CACGTG, we performed a targeted identification of a subset of putative bidirectional promoters to identify genes involved in seed development and to investigate possible coordinated responses of gene pairs to conditions important in seed maturation such as desiccation and ABA-regulation. We further characterized a pair of genes sharing an intergenic region that also contained a CE3 element and describe preliminary functional data implicating two small, previously uncharacterized, plantspecific proteins in Arabidopsis seed development and stress responses.

\section{Additional files}

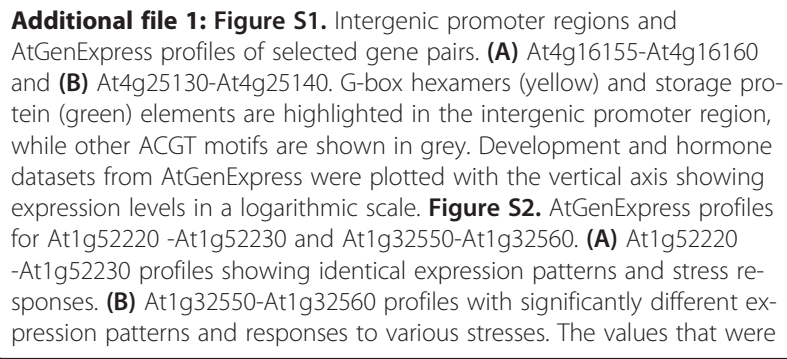

used were extracted from developmental, abiotic stress, hormones and light datasets with vertical axis showing expression levels in logarithmic scale. Figure S3. (A) Localisation of At3g03150 to the mitochondrion. Scale bar $20 \mu \mathrm{m}$. (B) Predicted transmembrane regions for At3g03160 using the TMHMM Server 2.0. (C) Schematic showing the organization of At3g03150 and At3g03160 paralogues on chromosome 5 (At5g17165 and At5g17190, respectively). (D) RT-PCR survey for the expression of the paralogues At5g17165 and At5g17190 using the same tissues as in Figure 2. RL, rosette leaf; $C L$, cauline leaf; R, root; ST, stem; FL, flower; SL, silique; gDNA, genomic DNA; -ve, negative control (water).

Additional file 2: Table S1. Accession numbers of sequences used in Figure 1B-C.

Additional file 3: Table S2. Sequences of all primers used in the present study.

Additional file 4: Table S3. Transmission efficiency through the male and female gametophyte in SALK_121507.

Additional file 5: File S1. AtGenExpress data extracted via the AVT. The data were used to make graphs in Additional file 1: Figures S1 and S2 and Figure 3.

\section{Competing interests}

The authors declare that they have no competing interests.

\section{Authors' contributions}

SK carried out gene expression and T-DNA line characterization; KL performed the bioinformatics work identifying the intergenic regions; $\mathrm{RH}$ initiated the T-DNA line and gene sequence analyses; PR performed protein localization experiments; TP contributed to RT-PCR gene expression and T-DNA line analyses; SK and SD designed the study and drafted the manuscript. All authors read and approved the final manuscript.

\section{Acknowledgements}

The authors would like to thank other members of the B/BASH bioinformatics unit in University of Leicester, Richard Badge and Matthew Blades. Work in the SD group is supported by the University of Leicester, The Leverhulme Trust and BBSRC. TP was a University of Leicester MSc. Molecular Genetics project student. We also acknowledge the work of Annabel Sturgess funded by a summer internship from The Genetics Society.

\section{Author details}

'Department of Biology, University of Leicester, University Road, Leicester LE1 7RH, UK. ${ }^{2}$ Bioinformatics and Biostatistics Analysis Support Hub (BBASH), College of Medicine, Biological Sciences and Psychology, University of Leicester, Leicester, UK. ${ }^{3}$ Current address UCL Business PLC, The Network Building, 97 Tottenham Court Road, London W1T 4TP, UK. ${ }^{4}$ Current address Department of Molecular, Cellular and Developmental Biology, Yale University, New Haven, CT 06520, USA.

Received: 16 July 2013 Accepted: 15 November 2013

Published: 22 November 2013

\section{References}

1. Trinklein ND, Aldred SF, Hartman SJ, Schroeder DI, Otillar RP, Myers RM: An abundance of bidirectional promoters in the human genome. Genome Res 2004, 14(1):62-66.

2. Dhadi SR, Krom N, Ramakrishna W: Genome-wide comparative analysis of putative bidirectional promoters from rice, Arabidopsis and Populus. Gene 2009, 429(1-2):65-73.

3. Wang $Q$, Wan L, Li D, Zhu L, Qian M, Deng M: Searching for bidirectional promoters in Arabidopsis thaliana. BMC Bioinformatics 2009, 10(Suppl 1):S29.

4. Chaturvedi CP, Sawant SV, Kiran K, Mehrotra R, Lodhi N, Ansari SA, Tuli R: Analysis of polarity in the expression from a multifactorial bidirectional promoter designed for high-level expression of transgenes in plants. J Biotechnol 2006, 123(1):1-12.

5. Mehrotra R, Gupta G, Sethi R, Bhalothia P, Kumar N, Mehrotra S: Designer promoter: an artwork of cis engineering. Plant Mol Biol 2011, 75(6):527-536.

6. Xie M, He Y, Gan S: Bidirectionalization of polar promoters in plants. Nat Biotech 2001, 19(7):677-679. 
7. Que Q, Chilton M-DM, de Fontes CM, He C, Nuccio M, Zhu T, Wu Y, Chen JS, Shi L: Trait stacking in transgenic crops: challenges and opportunities. GM Crops 2010, 1(4):220-229.

8. Wakano C, Byun JS, Di L-J, Gardner K: The dual lives of bidirectional promoters. Biochimica et Biophysica Acta (BBA) - Gene Regulatory Mechanisms 2012, 1897(7):688-693.

9. Wei W, Pelechano V, Järvelin Al, Steinmetz LM: Functional consequences of bidirectional promoters. Trends Genet 2011, 27(7):267-276.

10. Neil H, Malabat C, d/'Aubenton-Carafa Y, Xu Z, Steinmetz LM, Jacquier A: Widespread bidirectional promoters are the major source of cryptic transcripts in yeast. Nature 2009, 457(7232):1038-1042

11. Xu Z, Wei W, Gagneur J, Perocchi F, Clauder-Munster S, Camblong J, Guffanti E, Stutz F, Huber W, Steinmetz LM: Bidirectional promoters generate pervasive transcription in yeast. Nature 2009, 457(7232):1033-1037.

12. Bondino $H G$, Valle $E M$ : A small intergenic region drives exclusive tissuespecific expression of the adjacent genes in Arabidopsis thaliana. BMC Mol Biol 2009, 10:95

13. Mitra A, Han J, Zhang Z, Mitra A: The intergenic region of Arabidopsis thaliana cab1 and cab2 divergent genes functions as a bidirectional promoter. Planta 2009, 229(5):1015-1022.

14. Shin R, Kim MJ, Paek KH: The CaTin1 (Capsicum annuum TMV-induced clone 1) and CaTin1-2 genes are linked head-to-head and share a bidirectional promoter. Plant Cell Physiol 2003, 44(5):549-554.

15. Singh A, Sahi C, Grover A: Chymotrypsin protease inhibitor gene family in rice: genomic organization and evidence for the presence of a bidirectional promoter shared between two chymotrypsin protease inhibitor genes. Gene 2009, 428(1-2):9-19.

16. Yang MQ, Koehly LM, Elnitski LL: Comprehensive annotation of bidirectional promoters identifies co-regulation among breast and ovarian cancer genes. PLoS Comput Biol 2007, 3(4):e72

17. Cutler SR, Rodriguez PL, Finkelstein RR, Abrams SR: Abscisic acid: emergence of a core signaling network. Annual Rev Plant Biol 2010, 61(1):651-679.

18. Seki M, Kamei A, Yamaguchi-Shinozaki K, Shinozaki K: Molecular responses to drought, salinity and frost: common and different paths for plant protection. Curr Opin Biotechnol 2003, 14(2):194-199.

19. Chandrasekharan MB, Bishop KJ, Hall TC: Module-specific regulation of the $\beta$-phaseolin promoter during embryogenesis. Plant J 2003, 33(5):853-866.

20. Drea S: Characterization of two genes transcribed from a divergent promotor in Arabidopsis thaliana and encoding plastid-targeted proteins, PhD Thesis 2001. Ireland: Trinity College Dublin.

21. Keddie JS, Tsiantis M, Piffanelli P, Cella R, Hatzopoulos P, Murphy DJ: A seedspecific Brassica napus oleosin promoter interacts with a G-box-specific protein and may be bi-directional. Plant Mol Biol 1994, 24(2):327-340.

22. Hsieh W-P, Hsieh H-L, Wu S-H: Arabidopsis bZIP16 transcription factor integrates light and hormone signaling pathways to regulate early seedling development. Plant Cell Online 2012, 24(10):3997-4011.

23. Menkens AE, Schindler U, Cashmore AR: The G-box: a ubiquitous regulatory DNA element in plants bound by the GBF family of bZIP proteins. Trends Biochem Sci 1995, 20(12):506-510.

24. Hattori T, Totsuka M, Hobo T, Kagaya Y, Yamamoto-Toyoda A: Experimentally determined sequence requirement of ACGT-containing abscisic acid response element. Plant Cell Physiol 2002, 43(1):136-140.

25. Suzuki M, Ketterling MG, McCarty DR: Quantitative statistical analysis of cis-regulatory sequences in ABA/VP1- and CBF/DREB1-regulated genes of Arabidopsis. Plant Physiol 2005, 139(1):437-447.

26. Zhang W, Ruan J, Ho T-hD, You Y, Yu T, Quatrano RS: Cis-regulatory element based targeted gene finding: genome-wide identification of abscisic acid- and abiotic stress-responsive genes in Arabidopsis thaliana. Bioinformatics 2005, 21(14):3074-3081

27. Busk PK, Pagès M: Regulation of abscisic acid-induced transcription. Plant Mol Biol 1998, 37(3):425-435.

28. Lata C, Prasad M: Role of DREBs in regulation of abiotic stress responses in plants. J Exp Bot 2011, 62(14):4731-4748.

29. Yamaguchi-Shinozaki K, Shinozaki K: Organization of cis-acting regulatory elements in osmotic- and cold-stress-responsive promoters. Trends Plant Sci 2005, 10(2):88-94.

30. Drea SC, Lao NT, Wolfe KH, Kavanagh TA: Gene duplication, exon gain and neofunctionalization of OEP16-related genes in land plants. Plant J 2006, 46(5):723-735

31. Drea SC, Mould RM, Hibberd JM, Gray JC, Kavanagh TA: Tissue-specific and developmental-specific expression of an Arabidopsis thaliana gene encoding the lipoamide dehydrogenase component of the plastid pyruvate dehydrogenase complex. Plant Mol Biol 2001, 46(6):705-715.

32. Chen W, Chi Y, Taylor NL, Lambers H, Finnegan PM: Disruption of ptLPD1 or ptLPD2, genes that encode isoforms of the plastidial lipoamide dehydrogenase, confers arsenate hypersensitivity in Arabidopsis. Plant Physiol 2010, 153(3):1385-1397.

33. Pudelski B, Schock A, Hoth S, Radchuk R, Weber H, Hofmann J, Sonnewald U, Soll J, Philippar $K$ : The plastid outer envelope protein OEP16 affects metabolic fluxes during ABA-controlled seed development and germination. J Exp Bot 2012, 63:1919-1936.

34. Sadanandom A, Piffanelli P, Knott T, Robinson C, Sharpe A, Lydiate D, Murphy D, Fairbairn DJ: Identification of a peptide methionine sulphoxide reductase gene in an oleosin promoter from Brassica napus. Plant J 1996, 10(2):235-242.

35. Sadanandom A, Poghosyan Z, Fairbairn DJ, Murphy DJ: Differential regulation of plastidial and cytosolic isoforms of peptide methionine sulfoxide reductase in Arabidopsis. Plant Physiol 2000, 123(1):255-264.

36. Romero HM, Berlett BS, Jensen PJ, Pell EJ, Tien M: Investigations into the role of the plastidial peptide methionine sulfoxide reductase in response to oxidative stress in Arabidopsis. Plant Physiol 2004, 136(3):3784-3794.

37. Shimada TL, Shimada T, Takahashi H, Fukao Y, Hara-Nishimura I: A novel role for oleosins in freezing tolerance of oilseeds in Arabidopsis thaliana. Plant J 2008, 55(5):798-809.

38. Goda H, Sasaki E, Akiyama K, Maruyama-Nakashita A, Nakabayashi K, Li W, Ogawa M, Yamauchi Y, Preston J, Aoki K, et al: The AtGenExpress hormone and chemical treatment data set: experimental design, data evaluation, model data analysis and data access. Plant J 2008, 55(3):526-542.

39. Kilian J, Whitehead D, Horak J, Wanke D, Weinl S, Batistic O, D'Angelo C, Bornberg-Bauer E, Kudla J, Harter K: The AtGenExpress global stress expression data set: protocols, evaluation and model data analysis of UV-B light, drought and cold stress responses. Plant J 2007, 50(2):347-363.

40. Schmid M, Davison TS, Henz SR, Pape UJ, Demar M, Vingron M, Scholkopf B, Weigel D, Lohmann JU: A gene expression map of Arabidopsis thaliana development. Nat Genet 2005, 37(5):501-506.

41. Hall TA: BioEdit: a user-friendly biological sequence alignment editor and analysis program for Windows. Nucl Acids Symp Ser 1999, 41:95-98.

42. Thompson JD, Gibson TJ, Plewniak F, Jeanmougin F, Higgins DG: The CLUSTAL X windows interface: flexible strategies for multiple sequence alignment aided by quality analysis tools. Nucleic Acids Res 1997, 25(24):4876-4882.

43. Nakai K, Horton P: PSORT: a program for detecting sorting signals in proteins and predicting their subcellular localization. Trends Biochem Sci 1999, 24(1):34-35

44. Emanuelsson $\mathrm{O}$, Brunak $\mathrm{S}$, von Heijne $\mathrm{G}$, Nielsen $\mathrm{H}$ : Locating proteins in the cell using TargetP, SignalP and related tools. Nat Protocols 2007 2(4):953-971.

45. Higo K, Ugawa Y, Iwamoto M, Higo H: PLACE: A database of plant cis-acting regulatory DNA elements. Nucleic Acids Res 1998, 26(1):358-359.

46. Krogh A, Larsson B, von Heijne G, Sonnhammer EL: Predicting transmembrane protein topology with a hidden Markov model: application to complete genomes. J Mol Biol 2001, 305(3):567-580.

47. Kim J-S, Mizoi J, Yoshida T, Fujita Y, Nakajima J, Ohori T, Todaka D, Nakashima K, Hirayama T, Shinozaki $K$, et al: An ABRE promoter sequence is involved in osmotic stress-responsive expression of the DREB2A gene, which encodes a transcription factor regulating drought-inducible genes in arabidopsis. Plant Cell Physiol 2011, 52(12):2136-2146.

48. Clough SJ, Bent AF: Floral dip: a simplified method for Agrobacteriummediated transformation of Arabidopsis thaliana. Plant J 1998, 16(6):735-743.

49. Boisnard-Lorig C, Colon-Carmona A, Bauch M, Hodge S, Doerner P, Bancharel E, Dumas C, Haseloff J, Berger F: Dynamic analyses of the expression of the HISTONE::YFP fusion protein in arabidopsis show that syncytial endosperm is divided in mitotic domains. Plant Cell 2001, 13(3):495-509.

50. Alonso JM, Stepanova AN, Leisse TJ, Kim CJ, Chen H, Shinn P, Stevenson DK, Zimmerman J, Barajas $P$, Cheuk R, et al: Genome-wide Insertional mutagenesis of arabidopsis thaliana. Science 2003, 301(5633):653-657.

51. Howden R, Park SK, Moore JM, Orme J, Grossniklaus U, Twell D: Selection of T-DNA-tagged male and female gametophytic mutants by segregation distortion in arabidopsis. Genetics 1998, 149(2):621-631.

52. Boavida LC, McCormick S: Temperature as a determinant factor for increased and reproducible in vitro pollen germination in Arabidopsis thaliana. Plant J 2007, 52(3):570-582. 
53. Li Y-Y, Yu H, Guo Z-M, Guo T-Q, Tu K, Li Y-X: Systematic analysis of headto-head gene organization: evolutionary conservation and potential biological relevance. PLOS Comput Biol 2006, 2(7):e74.

54. Liu B, Chen J, Shen B: Genome-wide analysis of the transcription factor binding preference of human bi-directional promoters and functional annotation of related gene pairs. BMC Systems biol 2011, 5(Suppl 1):S2.

55. Borisjuk L, Rolletschek H, Radchuk R, Weschke W, Wobus U, Weber H: Seed development and differentiation: a role for metabolic regulation. Plant Biol (Stuttg) 2004, 6(4):375-386.

56. Grene R: Oxidative stress and acclimation mechanisms in plants, Volume 1. The Arabidopsis Book; 2002:e0036. doi:10.1199/tab.0036.1.

57. Pagnussat GC, Yu H-J, Ngo QA, Rajani S, Mayalagu S, Johnson CS, Capron A, Xie $L-F, Y e D$, Sundaresan V: Genetic and molecular identification of genes required for female gametophyte development and function in Arabidopsis. Development 2005, 132(3):603-614

58. Gaur T, Tyagi A: Analysis of arabidopsis PsbQ a gene expression in transgenic tobacco reveals differential role of its promoter and transcribed region in organ-specific and light-mediated regulation. Transgenic Res 2004, 13(2):97-108.

59. Wang SQ, Shi DQ, Long YP, Liu J, Yang WC: GAMETOPHYTE DEFECTIVE 1, a putative subunit of RNases P/MRP, is essential for female gametogenesis and male competence in Arabidopsis. PloS one 2012, 7(4):e33595.

60. Griffith ME, Mayer U, Capron A, Ngo QA, Surendrarao A, McClinton R, Jürgens $G$, Sundaresan V: The TORMOZ gene encodes a nucleolar protein required for regulated division planes and embryo development in arabidopsis. Plant Cell Online 2007, 19(7):2246-2263.

61. Van Damme D, De Rybel B, Gudesblat G, Demidov D, Grunewald W, De Smet I, Houben A, Beeckman T, Russinova E: Arabidopsis a aurora kinases function in formative cell division plane orientation. Plant Cell Online 2011, 23(11):4013-4024.

62. Bai X, Peirson BN, Dong F, Xue C, Makaroff CA: Isolation and characterization of SYN1, a RAD21-like gene essential for meiosis in arabidopsis. Plant Cell Online 1999, 11(3):417-430.

63. Choe S, Tanaka A, Noguchi T, Fujioka S, Takatsuto S, Ross AS, Tax FE, Yoshida S, Feldmann KA: Lesions in the sterol $\Delta 7$ reductase gene of Arabidopsis cause dwarfism due to a block in brassinosteroid biosynthesis. Plant J 2000, 21(5):431-443.

64. Hamasaki H, Yoshizumi T, Takahashi N, Higuchi M, Kuromori T, Imura Y, Shimada H, Matsui M: SD3, an Arabidopsis thaliana homolog of TIM21, affects intracellular ATP levels and seedling development. Mol Plant 2012, 5(2):461-471.

65. Olvera-Carrillo Y, Campos F, Reyes JL, Garciarrubio A, Covarrubias AA Functional analysis of the group 4 late embryogenesis abundant proteins reveals their relevance in the adaptive response during water deficit in arabidopsis. Plant Physiol 2010, 154(1):373-390.

66. Yu Q-B, Li G, Wang G, Sun J-C, Wang P-C, Wang C, Mi H-L, Ma W-M, Cui J, $C$ Cui $Y-L$, et al: Construction of a chloroplast protein interaction network and functional mining of photosynthetic proteins in Arabidopsis thaliana. Cell Res 2008, 18(10):1007-1019.

67. Gomez-Porras JL, Riano-Pachon DM, Dreyer I, Mayer JE, Mueller-Roeber B: Genome-wide analysis of ABA-responsive elements $A B R E$ and $C E 3$ reveals divergent patterns in Arabidopsis and rice. BMC Genomics 2007, 8:260.

68. Shaikhali J, Heiber I, Seidel T, Stroher E, Hiltscher H, Birkmann S, Dietz KJ, Baier M: The redox-sensitive transcription factor Rap2.4a controls nuclear expression of 2-Cys peroxiredoxin A and other chloroplast antioxidant enzymes. BMC Plant Biol 2008, 8:48.

69. Hobo T, Asada M, Kowyama Y, Hattori T: ACGT-containing abscisic acid response element (ABRE) and coupling element 3 (CE3) are functionally equivalent. Plant J 1999, 19(6):679-689.

70. Collett H, Shen A, Gardner M, Farrant JM, Denby KJ, Illing N: Towards transcript profiling of desiccation tolerance in Xerophyta humilis: Construction of a normalized $11 \mathrm{kX}$. humilis CDNA set and microarray expression analysis of 424 cDNAs in response to dehydration. Physiol Plant 2004, 122(1):39-53.

71. Blanc G, Barakat A, Guyot R, Cooke R, Delseny M: Extensive duplication and reshuffling in the Arabidopsis genome. Plant Cell 2000, 12(7):1093-1101.

72. Elo A, Lyznik A, Gonzalez DO, Kachman SD, Mackenzie SA: Nuclear genes that encode mitochondrial proteins for DNA and RNA metabolism are clustered in the Arabidopsis genome. Plant Cell 2003, 15(7):1619-1631.

73. Yang X, Winter CM, Xia X, Gan S: Genome-wide analysis of the intergenic regions in Arabidopsis thaliana suggests the existence of bidirectional promoters and genetic insulators. Current Topics Plant Biol 2011, 12:15-33.
74. Christensen CA, Subramanian S, Drews GN: Identification of gametophytic mutations affecting female gametophyte development in Arabidopsis. Dev Biol 1998, 202(1):136-151.

75. Liu P-P, Koizuka N, Homrichhausen TM, Hewitt JR, Martin RC, Nonogaki H: Large-scale screening of Arabidopsis enhancer-trap lines for seed germination-associated genes. Plant J 2005, 41(6):936-944.

76. Stangeland B, Salehian Z, Aalen R, Mandal A, Olsen OA: Isolation of GUS marker lines for genes expressed in Arabidopsis endosperm, embryo and maternal tissues. J Exp Bot 2003, 54(381):279-290.

77. Tzafrir I, Pena-Muralla R, Dickerman A, Berg M, Rogers R, Hutchens S, Sweeney TC, McElver J, Aux G, Patton D, et al: Identification of genes required for embryo development in Arabidopsis. Plant Physiol 2004, 135(3):1206-1220.

78. Vandepoele K, Quimbaya M, Casneuf T, De Veylder L, Van de Peer Y: Unraveling transcriptional control in arabidopsis using cis-regulatory elements and coexpression networks. Plant Physiol 2009, 150(2):535-546.

79. Mulako I, Farrant JM, Collett H, Illing N: Expression of Xhdsi-1VOC, a novel member of the vicinal oxygen chelate (VOC) metalloenzyme superfamily, is up-regulated in leaves and roots during desiccation in the resurrection plant Xerophyta humilis (Bak) Dur and Schinz. J Exp Bot 2008, 59(14):3885-3901.

80. DellaPenna D, O'Connor SE: Plant gene clusters and opiates. Science 2012, 336(6089):1648-1649.

81. West AB, Lockhart PJ, O'Farell C, Farrer MJ: Identification of a novel gene linked to parkin via a bi-directional promoter. J Mol Bio/ 2003, 326(1):11-19.

82. Taylor JM, Brody KM, Lockhart PJ: Parkin co-regulated gene is involved in aggresome formation and autophagy in response to proteasomal impairment. Exp Cell Res 2012, 318(16):2059-2070.

83. Horan K, Jang C, Bailey-Serres J, Mittler R, Shelton C, Harper JF, Zhu JK, Cushman JC, Gollery M, Girke T: Annotating genes of known and unknown function by large-scale coexpression analysis. Plant Physiol 2008,

147(1):41-57.

84. Heazlewood JL, Tonti-Filippini JS, Gout AM, Day DA, Whelan J, Millar AH: Experimental analysis of the Arabidopsis mitochondrial proteome highlights signaling and regulatory components, provides assessment of targeting prediction programs, and indicates plant-specific mitochondrial proteins. Plant Cell 2004, 16(1):241-256.

doi:10.1186/1471-2229-13-187

Cite this article as: Kourmpetli et al:: Bidirectional promoters in seed development and related hormone/stress responses. BMC Plant Biology 2013 13:187.

\section{Submit your next manuscript to BioMed Central and take full advantage of:}

- Convenient online submission

- Thorough peer review

- No space constraints or color figure charges

- Immediate publication on acceptance

- Inclusion in PubMed, CAS, Scopus and Google Scholar

- Research which is freely available for redistribution

Submit your manuscript at www.biomedcentral.com/submit
C Biomed Central 